\title{
Characterization of Some Spelt Wheat Starches as a Renewable Biopolymeric Material
}

\author{
Dorota Gałkowska, ${ }^{1}$ Teresa Witczak, ${ }^{2}$ Jarosław Korus, ${ }^{3}$ and Lesław Juszczak ${ }^{1}$ \\ ${ }^{1}$ Department of Analysis and Evaluation of Food Quality, University of Agriculture in Krakow, Balicka 122, 30-149 Krakow, Poland \\ ${ }^{2}$ Department of Engineering and Machinery for Food Industry, University of Agriculture in Krakow, Balicka 122, 30-149 Krakow, Poland \\ ${ }^{3}$ Department of Carbohydrate Technology, University of Agriculture in Krakow, Balicka 122, 30-149 Krakow, Poland
}

Correspondence should be addressed to Lesław Juszczak; rrjuszcz@cyf-kr.edu.pl

Received 31 October 2013; Accepted 19 December 2013; Published 5 February 2014

Academic Editors: A. Buzarovska, T. R. Chantara, and A. Uygun

\begin{abstract}
Copyright (C) 2014 Dorota Gałkowska et al. This is an open access article distributed under the Creative Commons Attribution License, which permits unrestricted use, distribution, and reproduction in any medium, provided the original work is properly cited.

The aim of this work was to analyze selected physical, chemical, thermal, and rheological properties of starches isolated from different spelt wheat varieties. The analyzed starches contained from 22.5 to $24.6 \mathrm{~g} / 100 \mathrm{~g}$ of amylose and from 45.9 to $50.6 \mathrm{mg} / 100 \mathrm{~g}$ of phosphorus. Ranges of characteristic gelatinization temperatures, $T_{O}, T_{P}$, and $T_{E}$, were $55.7-58.5^{\circ} \mathrm{C}, 61.1-62.6^{\circ} \mathrm{C}$, and $67.4-68.2^{\circ} \mathrm{C}$, respectively, while gelatinization enthalpy ranged from 8.87 to $9.96 \mathrm{~J} / \mathrm{g}$. The pasting curves showed significant differences in pasting characteristics of the starches. The values of maximum viscosity $\left(\eta_{\max }\right)$ and viscosity after cooling $\left(\eta_{50}\right)$ determined for the starch pastes were in the range of 82.3-100.7 B.U. and 149.3-172.7 B.U., respectively. The starch pastes demonstrated non-Newtonian, shear thinning flow behaviour and thixotropy phenomenon. After cooling the resulting starch gels were characterized by different viscoelastic properties, with a dominance of elastic features $\left(G^{\prime}>G^{\prime \prime}\right)$. The starches exhibited different tendency to retrogradation, with its degree $\left(R=\Delta H_{R} / \Delta H_{G}\right)$ in the range of $21.1-37.4 \%$.
\end{abstract}

\section{Introduction}

Spelt wheat (Triticim aestivum ssp. spelta) is one of the oldest subspecies of wheat that is used by humans. Spelt has already been cultivated about 7-8 thousand years BC. Numerous archeological discoveries in Europe areas prove that spelt wheat could be cultivated as a bread cereal in the eighth century BC [1]. Most likely it was created by the natural intersection of emmer wheat (Triticum dicoocum) and goatgrass species (Aegilops squarrosa) [1,2]. At the beginning of the 20th century spelt wheat was one of the most important cereals cultivated in Central Europe. Despite the close relationship to the widely grown wheat species, spelt wheat is very different from the last ones in terms of the many features. Spelt wheat kept largely the features of the wild cereals forms, that is, brittleness and fusion of grain with husk, which is beneficial for the survival and reproduction of the species, without human intervention. Nowadays, a significant increase of interest in cultivation of spelt wheat in Europe is observed $[1,2]$. The reason for this is growing consumers' demand for bread produced from this cereal species and a continuous increase in the number of farms focused on the production of organic food [2]. Spelt wheat involves very different, high-grade cereal species, extremely resistant to adverse weather conditions and diseases [3]. Therefore, it does not require the use of fertilizers or pesticides. Spelt wheat grain has strong hull that effectively protects the seed from contamination by pollutants from the atmosphere. Spelt wheat contains all the components necessary for proper functioning of the human body $[3,4]$. Increasing dieticians' interest in spelt wheat results from beneficial composition of spelt wheat grain $[5,6]$, which contains about $56 \%$ of starch. Still in the husk grain of spelt wheat contains more protein of higher degree of digestibility and biological quality as compared to common wheat grain $[4,7]$. Spelt wheat grain is also characterized by much higher fat content and its better quality comparing to other wheat species. Still in the husk grain contains about $2.7 \%$ of fat. Especially important components of spelt wheat are unsaturated fatty acids with predominantly linoleic, oleic, and palmitic acids [5]. Spelt 
wheat fat contains also more phytosterols than common wheat fat, making its consumption beneficial for lowering blood cholesterol level $[3,4]$. Mineral compounds content of spelt wheat amounts to about $2 \%$. There are especially much more phosphorus, zinc, copper, and selenium [4] contents as compared to other cereals. Spelt wheat (Triticum spelta) is a valuable source of vitamins. The spelt wheat derived vitamin E exhibits high biological activity that results from high level of alpha-tocopherol and much higher $\mathrm{B}$ vitamins contents as compared to common wheat $[3,4]$.

Starch, apart from cellulose, is the most common natural polysaccharide. Starches of different origin and their derivatives are the cheapest hydrocolloids. In food industry they are used as thickeners, texture building agents, fillers, and stabilizers [8]. Such a broad area of starch applications results from its special chemical structure and properties. The main raw materials for starch production are corn and potatoes; however, from the recent years the role of wheat as a starch source has significantly increased because of rising production of wheat gluten. Wheat starch exhibits a bimodal distribution of starch granules and high content of protein and lipid components. Such composition results in a decreased swelling capacity and elevated pasting temperature [9]. Native starch exists in a form of semicrystalline granules, which are insoluble in water. At low temperatures starch granules can reversibly swell in water. Heating above the so called pasting temperature leads to disintegration of internal structure of the granules, which is manifested by the loss of granular and crystalline structure. The resulting colloidal solution, which is called starch paste, can be regarded as a two-phase system, consisting of continuous phase built up by dissolved molecules of amylose and dispersed remnants of starch granules and branched amylopectin molecules. Depending on the concentration and pasting temperature starch forms a gel with special three-dimensional structure. The rheological properties of starch gels and pastes are especially important during processing of starch products. Starch pastes exhibit non-Newtonian, shear thinning flow behavior with a tendency to yield stress [10].

Increasing starch importance as a renewable raw material causes one's interest in the new sources of the starch. Wheat is an important raw material for starch industry, so investigations on properties of different wheat starch cultivars are still current. The purpose of the present study was to characterize some varieties of spelt wheat starch as a renewable biopolymeric material in respect of its physicochemical, thermal, and rheological properties.

\section{Material and Methods}

The materials were starches isolated from the following spelt wheat varieties: spelt wheat 8 (SWS1), spelt wheat 11 (SWS2), and spelt wheat STH 27-5597 (SWS3), which were obtained from Plant Breeding Strzelce, Ltd., Co., IHAR Group, as well as the following flours: spelt wheat flour ECCO 700 (Ecco-Food, Hungary) (SWS4), spelt wheat Śpaldova Mouka Celozrnna Hladka (Unibal, Liberec, Czech Republic) (SWS5), and spelt wheat 630 (SchapfenMühle GmbH \& Co KG,
Germany) (SWS6). Starches were isolated from the grains and flours by a laboratory method [11] with use of $0.1 \%$ $\mathrm{NaCl}$. The resulting starches were grinded in a laboratory grinder (Pulverisett 2, Fritsch, Germany) and sieved through a $0.125 \mathrm{~mm}$ mesh sieve.

\section{Physicochemical Properties}

The total nitrogen content and total protein content $(\mathrm{N} \times$ 6.00) were determined according to the Kjeldahl method [12]. Total lipid content was determined according to the Soxhlet method [13]. Apparent amylose content was determined by spectrophotometric method described by Morrison and Laignelet [14] using UV/Vis spectrophotometer (V-530, Jasco, Japan). Total phosphorus content was determined by spectrophotometric method according to ISO standard 3946 : 2000 [15]. Paste clarity was measured by spectrophotometric method. The starch suspension $(1 \mathrm{~g} / 100 \mathrm{~g})$ was heated at $95^{\circ} \mathrm{C}$ for $30 \mathrm{~min}$ in temperature controlled water bath with continuous stirring. After cooling to temperature of $25^{\circ} \mathrm{C}$, transmittance of the paste at wavelength of $\lambda=$ $640 \mathrm{~nm}$ against distilled water was measured using UV/Vis spectrophotometer (V-530, Jasco, Japan).

\section{Thermal Characteristics}

Thermodynamic gelatinization characteristics were determined using differential scanning calorimeter (DSC F204 Phoenix, Netzsch, Germany). Water-starch dispersion $(3: 1)$ was heated in the DSC aluminum pan in the temperature range of $25-110^{\circ} \mathrm{C}$ with heating rate of $10^{\circ} \mathrm{C} / \mathrm{min}$. The empty aluminum pan was used as a reference. On the basis of received thermograms the onset $\left(T_{O}\right)$, peak $\left(T_{P}\right)$, and endset $\left(T_{E}\right)$ gelatinization temperatures, as well as enthalpy of gelatinization $\left(\Delta H_{G}\right)$, were calculated. After cooling the sample was stored in refrigerator at $4 \pm 1^{\circ} \mathrm{C}$ for 7 days. Then the sample was reheated at the same conditions as for gelatinization. The onset $\left(T_{O}\right)$, peak $\left(T_{P}\right)$, endset $\left(T_{E}\right)$ temperatures, and enthalpy of retrogradation $\left(\Delta H_{R}\right)$ were calculated using Proteus Thermal Analysis software (Netzsch, Germany).

\section{Rheological Properties}

The intrinsic viscosity measurements were made at temperature of $25^{\circ} \mathrm{C}$. An amount of $1 \mathrm{~g}$ of starch was dissolved during stirring in 90\% DMSO during 24 hours at room temperature. The flow time of starch solutions was measured automatically by using an Ubbelohde capillary viscometer $(K=$ $0.004975 \mathrm{~m}^{2} / \mathrm{s}^{2}$ ) equipped with a ViscoClock system (Schott Instruments, Germany), over a concentration range of $0.048-$ $0.006 \mathrm{~g} / \mathrm{cm}^{3}$. Intrinsic viscosity was determined from the relationship between specific viscosity and concentration, described by the Huggins equation:

$$
\frac{\eta_{\mathrm{sp}}}{c}=[\eta]+k^{\prime}[\eta]^{2} \cdot c
$$

where $\eta_{\mathrm{sp}}$ is specific viscosity, $c$ is concentration $\left[\mathrm{g} / \mathrm{cm}^{3}\right],[\eta]$ is intrinsic viscosity $\left[\mathrm{cm}^{3} / \mathrm{g}\right]$, and $k^{\prime}$ is Huggins constant. 
TABle 1: Physicochemical characteristics of spelt wheat starches.

\begin{tabular}{|c|c|c|c|c|c|c|}
\hline Sample & $\begin{array}{l}\text { Protein content } \\
\quad(\mathrm{g} / 100 \mathrm{~g})\end{array}$ & $\begin{array}{c}\text { Crude fat content } \\
(\mathrm{g} / 100 \mathrm{~g})\end{array}$ & $\begin{array}{l}\text { Amylose content } \\
(\mathrm{g} / 100 \mathrm{~g})\end{array}$ & $\begin{array}{c}\text { Phosphorus } \\
\text { content }(\mathrm{mg} / 100 \mathrm{~g})\end{array}$ & Paste clarity (\%) & $\begin{array}{c}\text { Intrinsic viscosity } \\
\left(\mathrm{cm}^{3} / \mathrm{g}\right)\end{array}$ \\
\hline SWS 1 & $0.23 \pm 0.00$ & $0.56 \pm 0.01$ & $22.74 \pm 0.03$ & $48.70 \pm 0.24$ & $9.49 \pm 0.01$ & $151.17 \pm 0.63$ \\
\hline SWS 2 & $0.21 \pm 0.00$ & $0.57 \pm 0.01$ & $23.63 \pm 0.23$ & $48.50 \pm 0.00$ & $12.25 \pm 0.01$ & $133.94 \pm 0.26$ \\
\hline SWS 3 & $0.23 \pm 0.00$ & $0.47 \pm 0.01$ & $24.64 \pm 0.22$ & $45.88 \pm 0.39$ & $10.78 \pm 0.01$ & $138.36 \pm 0.23$ \\
\hline SWS 4 & $0.25 \pm 0.01$ & $0.51 \pm 0.01$ & $22.95 \pm 0.10$ & $50.63 \pm 0.26$ & $9.84 \pm 0.01$ & $142.67 \pm 1.82$ \\
\hline SWS 5 & $0.21 \pm 0.00$ & $0.49 \pm 0.00$ & $22.80 \pm 0.08$ & $47.70 \pm 0.00$ & $14.52 \pm 0.02$ & $142.26 \pm 0.50$ \\
\hline SWS 6 & $0.21 \pm 0.00$ & $0.44 \pm 0.00$ & $22.54 \pm 0.26$ & $49.05 \pm 0.13$ & $9.60 \pm 0.02$ & $155.61 \pm 0.47$ \\
\hline $\mathrm{LSD}_{0.05}$ & 0.01 & 0.02 & 0.31 & 0.40 & 0.03 & 1.49 \\
\hline
\end{tabular}

Pasting characteristics of starch were determined in Viscograph (ViscoAmyloGraph 803202, Brabender, Germany). Starch suspension of concentration of $6 \mathrm{~g} / 100 \mathrm{~g}$ was heated and then cooled with a speed of $1.5^{\circ} \mathrm{C} / \mathrm{min}$. On the basis of the experimental curve the following parameters were determined: pasting temperature $\left(T_{K}\right)$, maximum viscosity $\left(\eta_{\max }\right)$, minimum viscosity $\left(\eta_{\min }\right)$, viscosity after cooling to $50^{\circ} \mathrm{C}\left(\eta_{50}\right)$, and viscosity after $10 \mathrm{~min}$ holding at $50^{\circ} \mathrm{C}\left(\eta_{50 / 10}\right)$.

For the rheometric experiments (flow curves and sweep frequency tests) water-starch dispersion $(6 \mathrm{~g} / 100 \mathrm{~g})$ was heated at $95^{\circ} \mathrm{C}$ for $30 \mathrm{~min}$. The hot starch paste was put into the measuring system of rheometer, allowed to relax, and cooled to temperature of measurement.

The rotary viscometer Rheolab MCl (Physica, Germany) with a system of coaxial cylinders (cup diameter: $27.12 \mathrm{~mm}$, bob diameter: $25.00 \mathrm{~mm}$ ) was used for determination of flow curves at temperature of $50^{\circ} \mathrm{C}$ in the shear rate range from 1 to $500 \mathrm{~s}^{-1}$. The experimental curves were described by power law equation:

$$
\tau=K \cdot \dot{\gamma}^{n},
$$

where $\tau$ is shear stress $(\mathrm{Pa}), K$ is consistency coefficient $\left(\mathrm{Pa} \cdot \mathrm{s}^{n}\right), \dot{\gamma}^{n}$ is shear rate $\left(\mathrm{s}^{-1}\right)$, and $n$ is flow behavior index.

The sweep frequency test at $25^{\circ} \mathrm{C}$ was done using Mars II (Thermo-Haake, Germany) rheometer with cone/plate geometry (cone diameter: $60 \mathrm{~mm}$, angle: $1^{\circ}$, and gap size: $0.052 \mathrm{~mm}$ ). The test was performed at constant strain of 0.01 in the linear viscoelastic region and at angular frequency range of 1-100 rad/s. The power law equations were used to describe the experimental curves:

$$
\begin{aligned}
G^{\prime} & =K^{\prime} \cdot \omega^{n^{\prime}}, \\
G^{\prime \prime} & =K^{\prime \prime} \cdot \omega^{n^{\prime \prime}},
\end{aligned}
$$

where $G^{\prime}$ is storage modulus (Pa), $G^{\prime \prime}$ is loss modulus $(\mathrm{Pa}), \omega$ is angular frequency $(\mathrm{rad} / \mathrm{s})$, and $K^{\prime}, K^{\prime \prime}, n^{\prime}, n^{\prime \prime}$ are constants.

\section{Textural Properties}

Starch suspension of concentration of $10 \%$ was heated at temperature of $90^{\circ} \mathrm{C}$ for $30 \mathrm{~min}$ at continuous stirring. After cooling the resulting gel was stored at $5^{\circ} \mathrm{C}$ for 12 hours.
The textural properties of the gel were determined in EZ Test texture analyzer (Shimadzu, Japan). The gel sample was compressed twice with a probe speed of $50 \mathrm{~mm} / \mathrm{min}$ and with deformation of $50 \%$. Hardness, cohesiveness, elasticity, and gumminess were determined from the resulting curves.

\section{Statistical Analysis}

For statistical evaluation of the results the one-way analysis of variance at the significance level of 0.05 was performed. Significance of differences between the means was determined by Fisher LSD test at significance level of 0.05 .

\section{Results and Discussion}

Protein content in starch depends on botanical source of starch. It also depends on peptides, amino acids, amines, enzymes, and nucleic acids contents. Cereal starches, especially wheat starch, contain significantly more protein compounds as compared to potato starch. Protein content in the analyzed spelt wheat starches ranged from 0.21 to $0.25 \mathrm{~g} / 100 \mathrm{~g}$ (Table 1) and it was the greatest in the case of SWS4 sample. Slightly higher range of protein content in wheat starch was reported by Vansteelandt and Delcour [16]. Presence of protein compounds in starch affects its functional properties: swelling and solubility in water, gelatinization, and clarity of starch pastes. Fat content in the spelt wheat starches amounted from 0.44 to $0.57 \mathrm{~g} / 100 \mathrm{~g}$ (Table 1). Similar range of fat content for wheat starch was given by Vansteelandt and Delcour [16]. Similarly to protein compounds, fat compounds have significant effect on water holding capacity, swelling in water, and gelatinization of starch. Amylose content in starch is an essential parameter since it significantly affects functional properties of starch and the possibility of its use. Among the analyzed starches the highest amylose content was determined for SWS3 sample (Table 1). In the case of the other samples, amylose content was within the narrow limits and with a small statistical variation. Higher amylose contents in wheat starches were reported by Vansteelandt and Delcour [16] and Massaux et al. [17], while approximately equal amylose contents in starches from different wheat varieties were found by Raeker et al. [18]. Much wider ranges of amylose content in wheat starch and in different spelt wheat varieties were reported by Sasaki et al. [19] and Ie et al. [20], respectively. The ratio of amylose to amylopectin 
TABLE 2: Thermodynamic characteristics of gelatinization and retrogradation of spelt wheat starches.

\begin{tabular}{|c|c|c|c|c|c|c|c|c|}
\hline Sample & $T_{O}\left({ }^{\circ} \mathrm{C}\right)$ & $T_{P}\left({ }^{\circ} \mathrm{C}\right)$ & $T_{E}\left({ }^{\circ} \mathrm{C}\right)$ & $\Delta H_{G}(\mathrm{~J} / \mathrm{g})$ & $T_{\mathrm{OR}}\left({ }^{\circ} \mathrm{C}\right)$ & $T_{P R}\left({ }^{\circ} \mathrm{C}\right)$ & $T_{E R}\left({ }^{\circ} \mathrm{C}\right)$ & $\Delta H_{R}(\mathrm{~J} / \mathrm{g})$ \\
\hline SWS 1 & $57.9 \pm 0.0$ & $62.6 \pm 0.1$ & $67.8 \pm 0.1$ & $9.23 \pm 0.02$ & $40.4 \pm 0.3$ & $50.1 \pm 0.7$ & $60.8 \pm 0.6$ & $2.31 \pm 0.03$ \\
\hline SWS 2 & $57.9 \pm 0.0$ & $62.1 \pm 0.1$ & $67.8 \pm 0.1$ & $9.69 \pm 0.02$ & $41.0 \pm 0.2$ & $51.2 \pm 0.4$ & $60.0 \pm 0.4$ & $2.40 \pm 0.06$ \\
\hline SWS 3 & $58.5 \pm 0.1$ & $62.5 \pm 0.1$ & $67.9 \pm 0.1$ & $9.17 \pm 0.03$ & $41.0 \pm 0.2$ & $52.3 \pm 0.3$ & $59.9 \pm 0.0$ & $2.75 \pm 0.04$ \\
\hline SWS 4 & $57.8 \pm 0.1$ & $62.5 \pm 0.1$ & $68.2 \pm 0.1$ & $9.96 \pm 0.03$ & $43.9 \pm 0.1$ & $52.8 \pm 0.1$ & $60.5 \pm 0.2$ & $3.72 \pm 0.07$ \\
\hline SWS 5 & $57.9 \pm 0.1$ & $62.4 \pm 0.1$ & $67.9 \pm 0.1$ & $9.81 \pm 0.03$ & $43.4 \pm 0.2$ & $52.6 \pm 0.6$ & $59.6 \pm 0.2$ & $3.08 \pm 0.02$ \\
\hline SWS 6 & $55.7 \pm 0.1$ & $61.1 \pm 0.1$ & $67.4 \pm 0.1$ & $8.87 \pm 0.06$ & $42.6 \pm 0.5$ & $51.8 \pm 0.9$ & $58.6 \pm 0.4$ & $1.87 \pm 0.06$ \\
\hline $\mathrm{LSD}_{0.05}$ & 0.1 & 0.1 & 0.2 & 0.06 & 0.5 & 0.9 & 0.6 & 0.08 \\
\hline
\end{tabular}

in starch significantly affects its technological and functional properties. Starches with lower amylose content show higher value of peak viscosity and lower value of final viscosity in pasting characteristics. Starches with higher amylose content exhibit better thickening and gelling properties however; they are more susceptible to retrogradation [17]. On the other hand, food products with starch of higher amylopectin content show more stable texture, especially in freeze-thaw cycles. Among the mineral elements present in starch the most important is phosphorus, whose amount depends on botanical source of starch. In wheat starches phosphorus is present in the form of phospholipids, which can form complexes with amylose. Presence of phosphorus in starch determines many of its physical and chemical properties, as well as the differences in cereal starches and tuber or root starches. Phosphorus content in the analyzed starches was similar to each other and ranged from $45.88 \mathrm{mg} \mathrm{P} / 100 \mathrm{~g}$, for SWS3 sample, to $50.63 \mathrm{mg}$ P/100 g, for SWS4 (Table 1). That range of phosphorus content in the spelt wheat starches is in accordance with that reported by Franco et al. [21] for wheat starches. In Table 1 values of clarity of the $1 \%$ starch pastes, expressed as transmittance value, were also presented. The highest clarity was found for SWS5 sample. The transmittance values recorded for the spelt wheat starch pastes are in accordance with the literature data [22, 23]. High amount of amylose-lipids complexes in cereal starches is unfavorable in respect of clarity of starch pastes, since it results in their turbidity. This is confirmed in the present results. The SWS1 sample with high fat content showed the lowest clarity. Also high amount of protein compounds in starch is unfavorable for clarity of starch pastes, which was proved by low clarity of SWS4 sample.

Intrinsic viscosity is a parameter that is strictly correlated with molecular mass of polymer and in the case of starch it can be used for assessment of effects of different processes, for example, starch modification, on degradation of starch polymers. The lowest value of intrinsic viscosity was determined for SWS2 sample, while the highest one for SWS8 sample (Table 1).

One of characteristic properties of starch is its ability to gelatinize. Gelatinization temperature is a parameter characteristic for particular starch. Its value depends on starch to water ratio and size and crystallinity of starch granules, as well as on a degree of mechanical damage of the granules during heating. Higher pasting temperature can result from higher amount of longer amylopectin chains that require more energy input to their disintegration. Gelatinization process

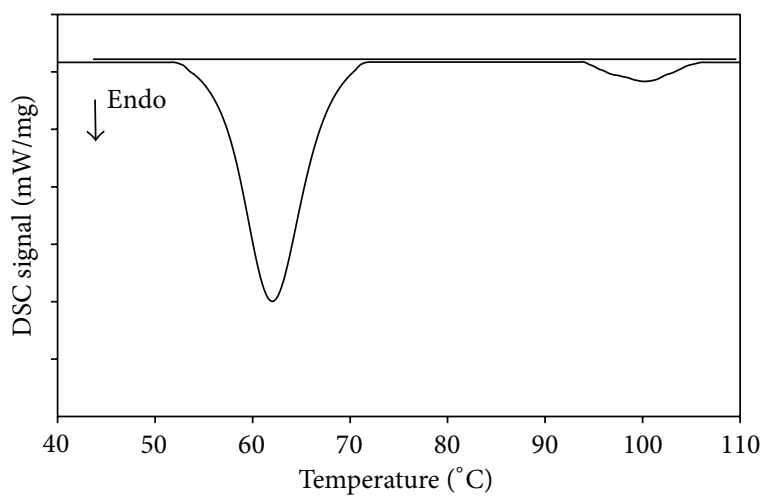

FIGURE 1: Typical DSC curve of spelt wheat starch pastes.

manifests in gradual loss in crystallinity of starch grains and loss of birefringence. Typical DSC curve of spelt wheat starch is shown in Figure 1. For all of the analyzed samples two endothermic peaks were obtained. First peak characterized gelatinization of starch granules, which is defined as a melting of the crystalline structure of starch, while the second one resulted from disintegration of amylose-lipids complexes. Parameters of thermodynamic pasting characteristics of starch samples were summarized in Table 2. Values of onset temperature ranged from 55.7 (for SWS6 starch) to $58.6^{\circ} \mathrm{C}$ (for SWS3 starch); values of peak temperature were in the range of $61.1-62.6^{\circ} \mathrm{C}$, while values of endset temperature were from 67.4 (for SWS6 starch) to $68.2^{\circ} \mathrm{C}$ (for SWS4 starch). The relatively small variation in the temperature range of the individual characteristics indicates similar structure and degree of crystallinity of the particular spelt wheat starches. Similar ranges and values of the characteristic gelatinization temperatures for starches isolated from different spelt wheat varieties were determined by Ie et al. [20], while Wilson et al. [24] reported similar values of onset temperature and slightly higher values of end temperature. Slightly lower values of the characteristic temperatures of thermal transition of wheat starch are given by Vansteelandt and Delcour [16], Franco et al. [21], and Chakraborty et al. [23]. Values of gelatinization enthalpy $(\Delta E)$ were from 8.87 to $9.96 \mathrm{~J} / \mathrm{g}$ for SWS6 and SWS4 starch, respectively. Gelatinization enthalpy is a measure for the total crystallinity of amylopectin and therefore a measure of amount and quality of starch crystallites. Chakraborty et al. [23] showed that starches having higher crystallinity had higher values of gelatinization enthalpy. In the present study the values of gelatinization enthalpy are in the lower region of 
TABle 3: Pasting characteristic of spelt wheat starches.

\begin{tabular}{lccccc}
\hline Sample & $T_{P}\left({ }^{\circ} \mathrm{C}\right)$ & $\eta_{\max }($ B.U. $)$ & $\eta_{\min }($ B.U. $)$ & $\eta_{50}($ B.U. $)$ & $149.3 \pm 6.5$ \\
\hline SWS 1 & $80.8 \pm 0.6$ & $82.3 \pm 4.0$ & $62.3 \pm 6.1$ & $159.3 \pm 9.1$ & $121.0 \pm 6.6$ \\
SWS 2 & $80.3 \pm 1.0$ & $87.7 \pm 1.2$ & $62.0 \pm 3.0$ & $155.3 \pm 2.5$ & $132.0 \pm 9.5$ \\
SWS 3 & $75.7 \pm 1.6$ & $88.0 \pm 1.0$ & $71.0 \pm 1.7$ & $172.7 \pm 10.1$ & $130.0 \pm 1.5$ \\
SWS 4 & $80.0 \pm 1.8$ & $100.7 \pm 6.7$ & $60.3 \pm 3.2$ & $165.0 \pm 2.6$ & $143.7 \pm 9.3$ \\
SWS 5 & $80.6 \pm 1.7$ & $88.3 \pm 1.2$ & $73.3 \pm 4.0$ & $151.7 \pm 2.1$ & $137.0 \pm 2.6$ \\
SWS 6 & $81.2 \pm 1.1$ & $96.7 \pm 1.5$ & 6.8 & 11.3 & $122.0 \pm 2.6$ \\
\hline LSD $_{0.05}$ & 2.8 & 5.9 &
\end{tabular}

the range given for spelt wheat starches by Wilson et al. [24] (8.2-13.2 J/g), while they are much higher than these reported by Ie at al. [20]. Higher values of gelatinization enthalpy determined for starches isolated from various varieties of common wheat are reported by Vansteelandt and Delcour [16] and Franco et al. [21], while Chakraborty et al. [23] give similar values of gelatinization enthalpy of wheat starches as compared to these determined in the present study. Characteristic feature of wheat starch gelatinization characteristics is the presence of the second endothermic peak that results from disintegration of amylose-lipids complexes. Values of the characteristic onset temperature ranged from $89.8^{\circ} \mathrm{C}$ (SWS6 starch) to $95.1^{\circ} \mathrm{C}$ (SWS1 starch); values of peak temperature were from 94.2 to $100.5^{\circ} \mathrm{C}$, while values of end temperature were in the range of $102.5-103.6^{\circ} \mathrm{C}$, for SWS4 and SWS1 starch, respectively. Values of enthalpy gelatinization were $0.32-0.95$ $\mathrm{J} / \mathrm{g}$ (data not given). Slightly higher onset temperature and similar values of peak and end temperatures for different spelt wheat starches were reported by Wilson et al. [24]. The above-mentioned authors give, however, higher values of gelatinization enthalpy of the process of disintegration of the amylose-lipids complexes. Higher values of gelatinization enthalpy for durum wheat starch are reported by Vansteelandt and Delcour [16]. In the present study significant linear correlations between crude fat content and onset temperature $(r=0.8122)$ or maximum peak ( $r=0.8237)$ of the process of thermal disintegration of amylose-lipids complexes, as well as between phosphorus content and enthalpy of disintegration of the complexes $(r=0.8283)$, were found.

During heating of starch water suspension the starch granules swell, amylose leaches from the granules, and a colloidal solution is formed, in which the continuous phase is composed of amylose dissolved in water with suspended fragments of starch granules composed mainly of amylopectin fraction [10]. When such system is cooled down a threedimensional network is formed as a result of forming of new hydrogen bonds that link glucan chains of starch and thus stabilize the internal structure of the system. Further cooling of such a system, with appropriate concentration of the starch, results in the formation of gel. During pasting of starch, above a characteristic temperature referred to as pasting temperature, viscosity of the starch suspension increases rapidly until reaching a maximum. Further heating, especially above $95^{\circ} \mathrm{C}$, leads to decrease in viscosity, and then during the cooling phase the viscosity increases. These changes are recorded in a form of pasting curves.
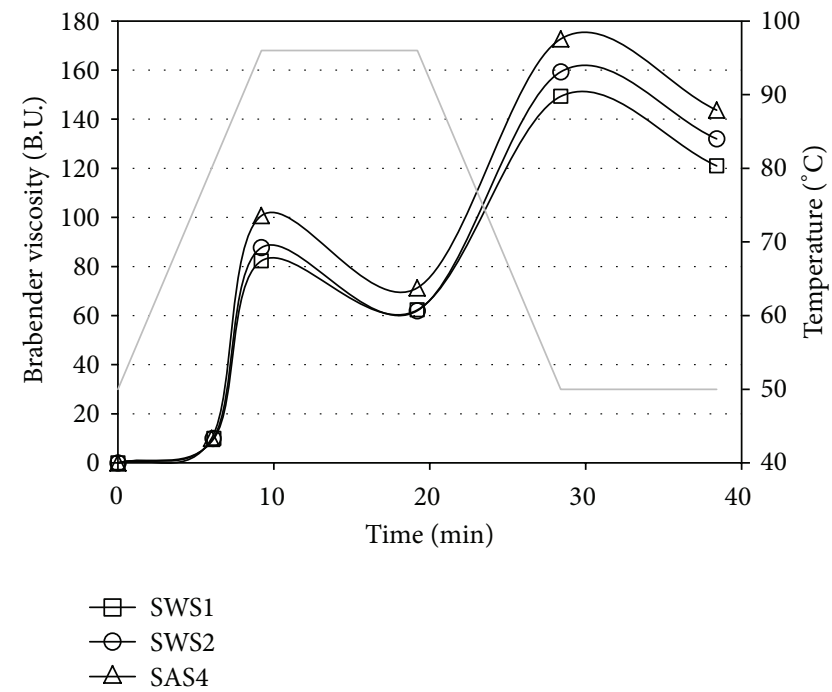

FIGURE 2: Typical pasting curves of spelt wheat starches.

Examples of the pasting curves of the analyzed starches are shown in Figure 2. These curves indicate differences in pasting characteristics of the spelt wheat starches. Shape of pasting curve of starch depends on, among others, amylose to amylopectin ratio. Amylopectin affects the increase in viscosity of starch pastes since it ensures the swelling of starch granules. On the other hand, amylose affects the decrease in swelling capacity of starch because of reinforcing effect on the internal structure of the starch granules. In the case of wheat starch the factor that determines pasting of starch, apart from protein and fat compounds, is quantitative ratio of A to B granules. Pasting temperatures of the analyzed starches were slightly differentiated and ranged from 75.7 to $81.2^{\circ} \mathrm{C}$, with the lowest one and significantly different from the other temperatures determined for SWS3 starch (Table 3). Slightly higher ranges of pasting temperatures for spelt wheat starches are given by Wilson et al. [24]. Higher pasting temperatures of wheat starch than potato starch result from significantly lower swelling capacity of cereal starches. In the present study a significant negative linear correlation between phosphorus content and pasting temperature $(r=$ -0.9249 ) was found. Viscosity of starch paste increases to maximum viscosity with increase in temperature, as a result of swelling of starch granules. The highest value of maximum viscosity was shown by SWS4 sample, while the lowest one by 
TABLE 4: Parameters of rheological models describing flow and viscoelastic behavior of spelt wheat starch pastes and gels.

\begin{tabular}{|c|c|c|c|c|c|c|c|c|c|}
\hline \multirow{2}{*}{ Sample } & \multicolumn{3}{|c|}{$\tau=K \cdot \dot{\gamma}^{n}$} & \multicolumn{3}{|c|}{$G^{\prime}=K^{\prime} \cdot \omega^{n^{\prime}}$} & \multicolumn{3}{|c|}{$G^{\prime \prime}=K^{\prime \prime} \cdot \omega^{n^{\prime \prime}}$} \\
\hline & $K\left(\mathrm{~Pa} \cdot \mathrm{s}^{n}\right)$ & $n$ & $R^{2}$ & $K^{\prime}$ & $n^{\prime}$ & $R^{2}$ & $K^{\prime \prime}$ & $n^{\prime \prime}$ & $R^{2}$ \\
\hline SWS 1 & $53.72 \pm 2.00$ & $0.23 \pm 0.01$ & 0.9644 & $111.59 \pm 8.76$ & $0.15 \pm 0.01$ & 0.9868 & $15.90 \pm 1.07$ & $0.28 \pm 0.02$ & 0.9980 \\
\hline SWS 2 & $45.58 \pm 2.25$ & $0.24 \pm 0.01$ & 0.9738 & $105.60 \pm 2.48$ & $0.17 \pm 0.01$ & 0.9948 & $17.12 \pm 1.52$ & $0.31 \pm 0.01$ & 0.9976 \\
\hline SWS 3 & $18.04 \pm 0.94$ & $0.36 \pm 0.01$ & 0.9915 & $119.87 \pm 3.20$ & $0.17 \pm 0.01$ & 0.9922 & $18.43 \pm 0.96$ & $0.31 \pm 0.01$ & 0.9977 \\
\hline SWS 4 & $26.48 \pm 1.03$ & $0.30 \pm 0.01$ & 0.9790 & $79.29 \pm 3.43$ & $0.17 \pm 0.01$ & 0.9941 & $13.06 \pm 1.10$ & $0.31 \pm 0.01$ & 0.9988 \\
\hline SWS 5 & $23.19 \pm 0.60$ & $0.33 \pm 0.01$ & 0.9885 & $96.55 \pm 6.48$ & $0.17 \pm 0.02$ & 0.9913 & $15.37 \pm 0.72$ & $0.29 \pm 0.01$ & 0.9992 \\
\hline SWS 6 & $19.99 \pm 0.28$ & $0.34 \pm 0.01$ & 0.9965 & $141.54 \pm 5.38$ & $0.18 \pm 0.01$ & 0.9852 & $21.78 \pm 1.85$ & $0.29 \pm 0.03$ & 0.9976 \\
\hline $\mathrm{LSD}_{0.05}$ & 2.43 & 0.02 & & 9.54 & 0.02 & & 2.22 & 0.03 & \\
\hline
\end{tabular}

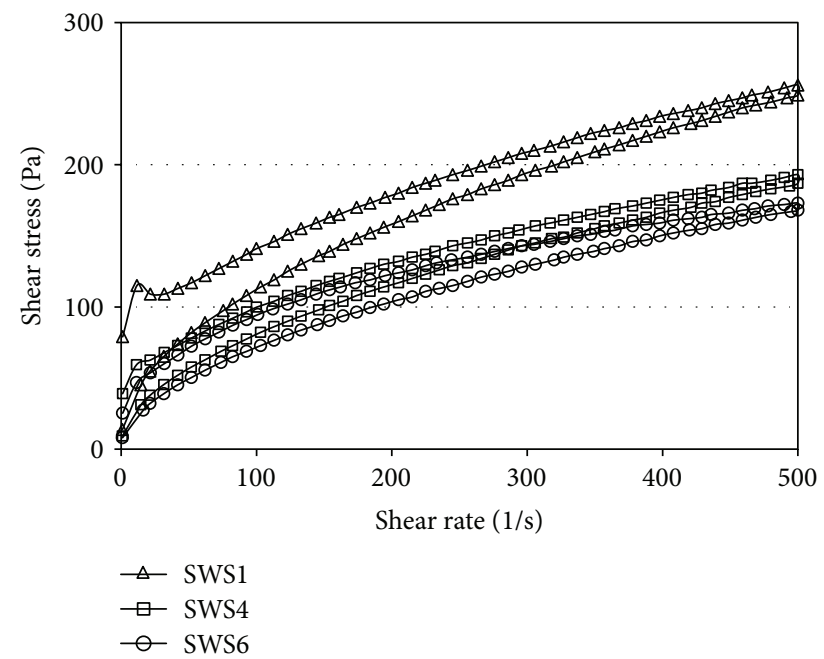

FIgURE 3: Examples of flow curves of spelt wheat starch pastes.

SWS1 sample (Table 3). During holding of the starch pastes at elevated temperature a decrease in viscosity is observed, which proves that the starch paste has reduced stability at elevated temperature [17]. Values of the decrease in viscosity (breakdown) for the analyzed starches ranged from 20 to 29 B.U. and were significantly correlated with values of maximum viscosity $(r=0.8250)$. Reduction in temperature to $50^{\circ} \mathrm{C}$ has a significant effect on the most important changes in viscosity. All the analyzed starch pastes after cooling to $50^{\circ} \mathrm{C}$ exhibited the highest values of viscosity of the entire course of pasting characteristics, being significantly higher than the respective values of maximum viscosity. The greatest viscosity at $50^{\circ} \mathrm{C}$ was shown by SWS 4 sample, while the smallest one by SWS1 sample. The size of the viscosity increase after cooling of the starch paste to $50^{\circ} \mathrm{C}$ was $78-105 \mathrm{~B}$.U. Holding of the starch pastes at $50^{\circ} \mathrm{C}$ for $10 \mathrm{~min}$ caused a decrease in their viscosity, proving limited resistance of the pastes to shearing forces. The size of that decrease was from 25 to 30 B.U.

Examples of typical flow curves of the starch pastes are shown in Figure 3. The samples exhibited non-Newtonian, shear thinning flow behaviour, with tendency to yield stress. Such a rheological character of starch pastes is considered as typical, which is proved by much literature data $[8,10$, $25,26]$. Moreover, the pastes exhibited rheological instability, called thixotropy, which is demonstrated in the form of hysteresis loops with increasing and decreasing shear rate. The shear thinning flow behaviour of starch pastes is a result of destruction of the entangled network of polysaccharide molecules forming kind of structure stabilized by hydrogen bonds. During shinning with increasing shear rates the rate of rupture of the existing intermolecular bonds is greater than the rate of recreation of these bonds, which demonstrates reduction of the shear resistance and, consequently, causes a decrease in the apparent viscosity [26].

Flow curves of the analyzed starches were described by power law model (Formula (2)), and the values of the determined parameters are summarized in Table 4. Consistency coefficient $K$ is a measure of the initial viscosity of the starch paste. The higher its value is, the more viscous the paste is. The highest value of consistency coefficient was found for SWS1 starch $\left(53.72 \mathrm{~Pa} \cdot \mathrm{s}^{n}\right)$, while the lowest one for SWS3 $\left(18.04 \mathrm{~Pa} \cdot \mathrm{s}^{n}\right)$. An important factor affecting viscosity of starch pastes is amylose to amylopectin ratio. Xie et al. [27] found that the greater the amylose content is, the higher viscosity the starch paste exhibits. Another important factor is presence of nonstarch components. In the present study a significant linear correlation between fat content and value of consistency coefficient was stated $(r=0.9315)$. Flow behaviour index is a measure of a deviation of rheological properties of fluid from Newtonian flow behaviour. In the case of all the analyzed starches the values of flow behaviour index were less than one and ranged from 0.23 to 0.36 , indicating that the starch pastes exhibited non-Newtonian, shear thinning flow behaviour. Significant negative linear correlation between fat content and values of flow behavior index $(r=-0.9572)$ was found. Thixotropy hysteresis of the flow curves reflects the degree of destruction and reconstruction of the structure of starch paste during shearing. All the starch pastes under study showed thixotropy phenomenon (Figure 3).

Viscoelastic properties of material result from presence of structures capable of partially storing the energy supplied, which after removal of the applied stress is recovered. In practice, part of the supplied energy is dissipated, and after removal of the stress it is not recovered. Therefore, the real materials show viscoelastic properties. The parameters that characterize the share of elastic and viscous properties of material are storage modulus $\left(G^{\prime}\right)$, representing that part of energy that is stored in the material, and loss modulus $\left(G^{\prime \prime}\right)$, representing that part of energy that is dissipated during viscous flow of the material. In Figure 4, the curves of storage 
TABLE 5: Textural properties of spelt wheat starch gels.

\begin{tabular}{lcccc}
\hline Sample & Hardness $(\mathrm{N})$ & Cohesiveness & Springiness & Gumminess (N) \\
\hline SWS 1 & $18.24 \pm 0.48$ & $0.26 \pm 0.01$ & $0.65 \pm 0.03$ & $1.68 \pm 0.07$ \\
SWS 2 & $23.85 \pm 3.68$ & $0.27 \pm 0.04$ & $0.26 \pm 0.02$ & $6.21 \pm 0.12$ \\
SWS 3 & $27.54 \pm 0.26$ & $0.19 \pm 0.00$ & $0.56 \pm 0.02$ & $5.24 \pm 0.04$ \\
SWS 4 & $36.55 \pm 1.06$ & $0.28 \pm 0.04$ & $0.65 \pm 0.02$ & $9.32 \pm 0.79$ \\
SWS 5 & $14.26 \pm 1.66$ & $0.25 \pm 0.01$ & $0.73 \pm 0.04$ & $3.12 \pm 0.36$ \\
SWS 6 & $18.52 \pm 0.47$ & $0.26 \pm 0.00$ & $0.64 \pm 0.02$ & $4.86 \pm 0.10$ \\
\hline LSD $_{0.05}$ & 2.23 & 0.03 & 0.04 & 0.55 \\
\hline
\end{tabular}

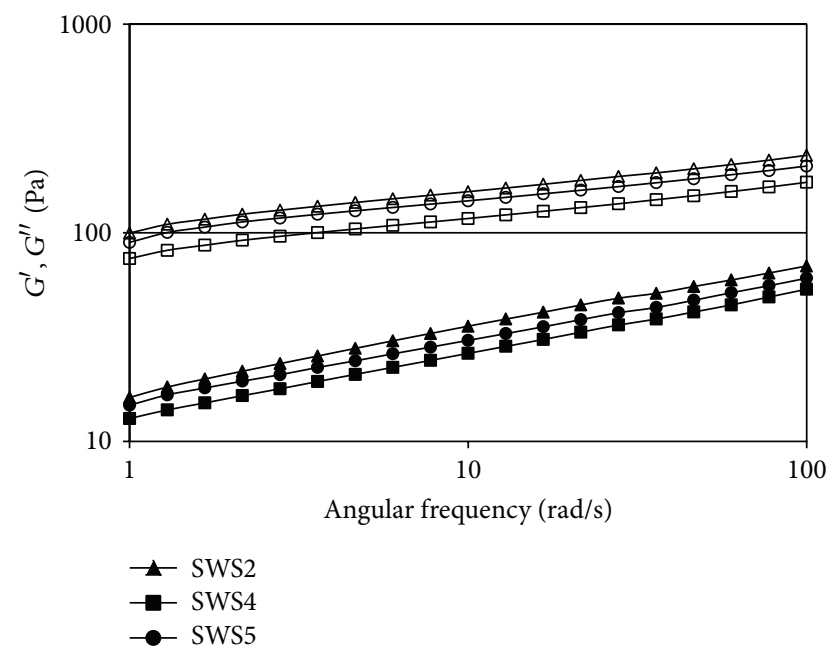

FIGURE 4: Examples of mechanical spectra of spelt wheat starch gels.

and loss moduli in function of angular frequency for three examples of spelt wheat starch gels are presented. The parameters of power law models describing the above-mentioned curves are summarized in Table 4. For all the starch gels values of storage modulus were higher than these of loss modulus within whole angular frequency range, which reflects that the elastic properties of the samples dominated over the viscous ones. Among the analyzed starch gels the lowest values of both moduli were stated for SWS4 sample, while the highest ones for SWS6 sample. The initial values of storage modulus $\left(G^{\prime}\right)$ and loss modulus $\left(G^{\prime \prime}\right)$ provide values of $K^{\prime}$ and $K^{\prime \prime}$ parameters that are presented in Table 4. Values of $K^{\prime}$ and $K^{\prime \prime}$ parameters ranged from 79.29 to 141.54 and from 13.06 to 21.78 , respectively. Values of loss tangent $\left(\tan \delta=G^{\prime \prime} / G^{\prime}\right)$ at angular frequency of $1 \mathrm{rad} / \mathrm{s}$ were in a narrow range of 0.140.16 . It reflects that the starches in the concentration used formed weak gels $(\tan \delta=0.1)$. Values of $n^{\prime}$ parameter ranged from 0.24 to 0.36 , while the differences between values of $n^{\prime \prime}$ parameter were inconsiderable. Significant factor affecting viscoelastic properties of starches is amylose to amylopectin ratio. Sasaki et al. [19, 28] observed that starch gels with high share of amylopectin are softer and weaken as compared to the gels of starches with greater amount of amylose.

Examples of texture profiles determined for two starches (SWS4 and SWS5) are presented in Figure 5. They showed extremely high values of hardness, expressed as force required for destroying the gel structure. The texture profiles of

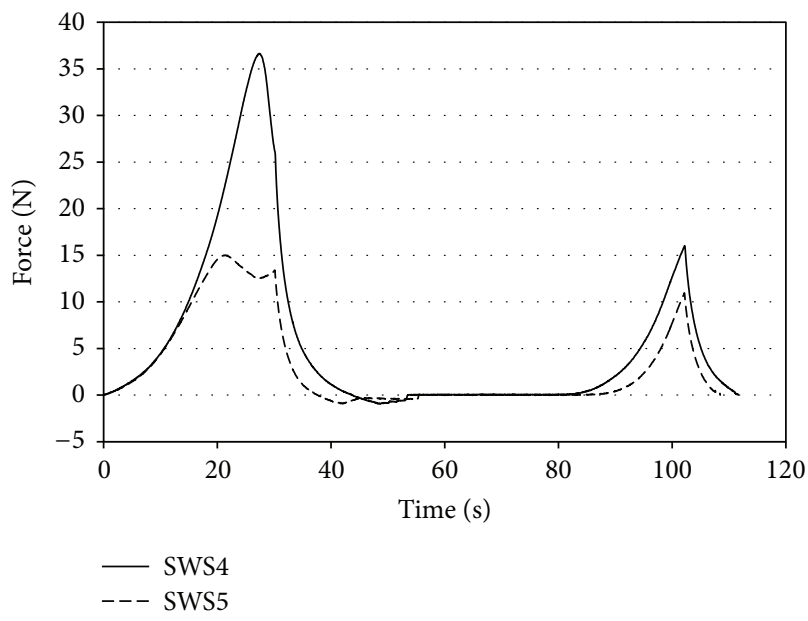

FIGURE 5: Examples of TPA curves of spelt wheat starch gels.

the other samples were similar in shape, with intermediate hardness values. In Table 5, values of the parameters of texture profile analysis (TPA) were presented. Texture of the starch gels reflects their structure and physicochemical and rheological properties. Texture can be described by such parameters as hardness, cohesiveness, elasticity, and gumminess. Hardness of starch gels increases over time of storage, because the amount of crystalline regions increases, and the amount of cross-linking between the polymer molecules via hydrogen bonds, that is, related to starch retrogradation, also increases. Hardness of the analyzed gels was from $14.26 \mathrm{~N}$, for SWS5 starch, to $36.55 \mathrm{~N}$, for SWS4 starch (Table 5). The greater the gel hardness is, the greater the force is required to disintegrate the structure of the gel. Cohesiveness of starch gel is a measure of difficulty in destroying the initial gel structure. Among the studied starch gels, the highest value of cohesiveness, similarly to hardness, was found for SWS4 starch. Elasticity of the material is expressed as a speed with which the sample returns to its initial structure after removal of the applied stress. The highest elasticity was showed by SWS5 starch gel, while the lowest one by SWS2 starch gel. According to Karam et al. [29] a decisive factor in the occurrence of elasticity of the starch gels is interactions between fragments of swollen starch granules and continuous phase composed of particles of dispersed amylose. A proof of significant effect of amylose content on elasticity of starch gel is high linear correlation $(r=0.9260)$ between these two parameters. Gumminess is a parameter that is closely 
correlated with hardness $(r=0.9345)$ and the highest value of that parameter was found for SWS4 starch gel.

Starch retrogradation is a phenomenon that results from formation of new hydrogen bonds between starch chains and the resulting aggregation of the polymers. During retrogradation amylose forms double helices composed of 40-70 glucose molecules [7], while recrystallization of amylopectin is a result of interactions between the outer amylopectin branch chains. During heating of starch gel which was previously stored in cooling conditions for a given time, an endothermic peak with characteristic temperatures lower of $10-20^{\circ} \mathrm{C}$ from pasting temperature range is observed [7]. This peak is a measure of energy required for disintegration of the recrystallized amylopectin. According to Singh et al. [7] values of retrogradation enthalpy are $60-80 \%$ lower than gelatinization enthalpy. In Table 2 values of characteristic phase transition temperatures and retrogradation enthalpy are given. The onset temperature ranged from 40.4 (SWS1 starch) to $43.9^{\circ} \mathrm{C}$ (SWS4 starch). Differentiation between the samples was much lower in the case of values of transition peak and endset temperature. A similar range of onset temperature, but slightly lower values of peak and endset temperature, was given by Yoo and Jane [30]. The ranges of temperatures of endothermic transition associated with the disintegration of the recrystallized amylopectin reported in the literature may slightly vary due to different initial concentration of starch in the gels and different storage times and temperatures. Values of retrogradation enthalpy ranged from $1.87 \mathrm{~J} / \mathrm{g}$ to $3.72 \mathrm{~J} / \mathrm{g}$, for SWS6 and SWS4 starch samples, respectively, and were lower than these reported by Yoo and Jane [30]. The rate of retrogradation ( $R \%)$, expressed as ratio of $\Delta H_{R}$ to $\Delta H_{G}$, was from 21.1 (for SWS6 starch) to $37.4 \%$ (for SWS4 starch). An essential factor that affects retrogradation of starch is structure of amylopectin and degree of polymerization of its chains. Longer branch chains significantly contribute to retrogradation rate and creation of the structures of greater crystallinity [30].

\section{Conclusions}

Spelt wheat starches of various botanical sources showed different physical, chemical, thermal, and rheological properties. The factors that have significant impact on the properties of starch are nonstarch compounds and amylose contents and structure of amylopectin. The pastes of the spelt wheat starches showed non-Newtonian, shear thinning flow behaviour and thixotropy phenomenon. After cooling the resulting starch gels were characterized by different viscoelastic properties, with a dominance of elastic features $\left(G^{\prime}>G^{\prime \prime}\right)$. The starches exhibited different tendency to retrogradation. On the basis of the obtained results and their comparison with the literature data concerning wheat starch characteristics it can be stated that spelt wheat grains can be good source of wheat starch due to its limited agrotechnical requirements.

\section{Conflict of Interests}

The authors declare that there is no conflict of interests regarding the publication of this paper.

\section{Acknowledgment}

The authors kindly thank the Plant Breeding Strzelce, Ltd., Co., IHAR Group, for providing the samples of spelt wheat grains used in this study.

\section{References}

[1] T. Bojňanská and H. Frančáková, "The use of spelt wheat (Triticum spelta L.) for baking applications," Rostlinná Výroba, vol. 48, no. 4, pp. 141-147, 2002.

[2] H. Sulewska, W. Koziara, K. Panasiewicz, G. Ptaszyńska, and M. Mrozowska, "Chemical composition of grain and protein yield of spelt varieties depended on selected agrotechnical factors," Journal of Research and Applications in Agriculture Engineering, vol. 53, no. 4, pp. 92-95, 2008.

[3] G. Bonafaccia, V. Galli, R. Francisci, V. Mair, V. Skrabanja, and I. Kreft, "Characteristics of spelt wheat products and nutritional value of spelt wheat-based bread," Food Chemistry, vol. 68, no. 4, pp. 437-441, 2000.

[4] Z. Kohajdová and J. Karovičová, "Nutritional value and baking applications of spelt wheat," Acta Scientiarum Polonorum, Technologia Alimentaria, vol. 7, no. 3, pp. 5-14, 2008.

[5] A. Ceglińska and W. Gromulska, "Różnorodność produktów Z orkiszu," Przegląd Zbożowo-Młynarski, vol. 5, pp. 30-31, 2008.

[6] H. Zieliński, A. Ceglińska, and A. Michalska, "Bioactive compounds in spelt bread," European Food Research and Technology, vol. 226, no. 3, pp. 537-544, 2008.

[7] N. Singh, J. Singh, L. Kaur, N. S. Sodhi, and B. S. Gill, "Morphological, thermal and rheological properties of starches from different botanical sources," Food Chemistry, vol. 81, no. 2, pp. 219-231, 2003.

[8] K. Pycia, L. Juszczak, D. Gałkowska, and M. Witczak, "Physicochemical properties of starches obtained from Polish potato cultivars," Starch/Stärke, vol. 64, no. 2, pp. 105-114, 2012.

[9] E. Escarnot, J. M. Jacquemin, R. Agneessens, and M. Paquot, "Comparative study of the content and profiles of macronutrients in spelt and wheat, a review," Biotechnologie, Agronomie, Société et Environnement, vol. 16, no. 2, pp. 243-256, 2012.

[10] L. Juszczak, M. Witczak, T. Zięba, and T. Fortuna, "Rheological behavior of heated potato starch dispersion," International Agrophysics, vol. 26, no. 4, pp. 381-386, 2012.

[11] M. Richter, S. Augustat, and F. Schierbaum, Ausgewähle Metoden der Stärkechemie, VEB Fachbuchverlag, Leipzing, Germany, 1968.

[12] PN-EN ISO 3188:2000, "Starches and derived products. Determination of nitrogen content by the Kjeldahl methodtitrimetric method".

[13] PN-EN ISO 3947:2001, "Starches and derived products. Determination of total fat content".

[14] W. R. Morrison and B. Laignelet, "An improved colorimetric procedure for determining apparent and total amylose in cereal and other starches," Journal of Cereal Science, vol. 1, no. 1, pp. 9-20, 1983.

[15] ISO 3946:2000, "Starches and derived products. Determination of total phosphorus content-spectrophotometric method".

[16] J. Vansteelandt and J. A. Delcour, "Characterisation of starch from durum wheat (Triticum durum)," Starch/Stärke, vol. 51, no. 2-3, pp. 73-80, 1999.

[17] C. Massaux, M. Sindic, J. Lenartz et al., "Variations in physicochemical and functional properties of starches extracted from 
European soft wheat (Triticum aestivum L.): the importance to preserve the varietal identity," Carbohydrate Polymers, vol. 71, no. 1, pp. 32-41, 2008.

[18] M. Ö. Raeker, C. S. Gaines, P. L. Finney, and T. Donelson, "Granule size distribution and chemical composition of starches from 12 soft wheat cultivars," Cereal Chemistry, vol. 75, no. 5, pp. 721-728, 1998.

[19] T. Sasaki, T. Yasui, J. Matsuki, and T. Satake, "Comparison of physical properties of wheat starch gels with different amylose content," Cereal Chemistry, vol. 79, no. 6, pp. 861-866, 2002.

[20] P. S. Ie, D. Petros, D. H. Stinner et al., "Comparison of the gelatinization behavior of organic and conventional spelt starches assessed by thermal and rheological analyses," Journal of Agricultural and Food Chemistry, vol. 60, no. 36, pp. 92299235, 2012.

[21] C. M. L. Franco, K.-S. Wong, S.-H. Yoo, and J.-L. Jane, "Structural and functional characteristics of selected soft wheat starches," Cereal Chemistry, vol. 79, no. 2, pp. 243-248, 2002.

[22] P. van Hung and N. Morita, "Effects of granule sizes on physicochemical properties of cross-linked and acetylated wheat starches," Starch/Stärke, vol. 57, no. 9, pp. 413-420, 2005.

[23] M. Chakraborty, K. Matkovic, D. G. Grier et al., "Physicochemical and functional properties of tetraploid and hexaploid waxy wheat starch," Starch/Stärke, vol. 56, no. 8, pp. 339-347, 2004.

[24] J. D. Wilson, D. B. Bechtel, G. W. T. Wilson, and P. A. Seib, "Bread quality of spelt wheat and its starch," Cereal Chemistry, vol. 85, no. 5, pp. 629-638, 2008.

[25] S. Lagarrigue and G. Alvarez, "The rheology of starch dispersions at high temperatures and high shear rates: a review," Journal of Food Engineering, vol. 50, no. 4, pp. 189-202, 2001.

[26] D. Yoo and B. Yoo, "Rheology of rice starch-sucrose composites," Starch/Stärke, vol. 57, no. 6, pp. 254-261, 2005.

[27] F. Xie, L. Yu, B. Su et al., "Rheological properties of starches with different amylose/amylopectin ratios," Journal of Cereal Science, vol. 49, no. 3, pp. 371-377, 2009.

[28] T. Sasaki, T. Yasui, J. Matsuki, and T. Satake, "Rheological properties of mixed gels using waxy and non-waxy wheat starch," Starch/Stärke, vol. 54, no. 9, pp. 410-414, 2002.

[29] L. B. Karam, M. V. E. Grossmann, R. S. S. F. Silva, C. Ferrero, and N. E. Zaritzky, "Gel textural characteristics of corn, cassava and yam starch blends: a mixture surface response methodology approach," Starch/Stärke, vol. 57, no. 2, pp. 62-70, 2005.

[30] S.-H. Yoo and J.-L. Jane, "Structural and physical characteristics of waxy and other wheat starches," Carbohydrate Polymers, vol. 49, no. 3, pp. 297-305, 2002. 

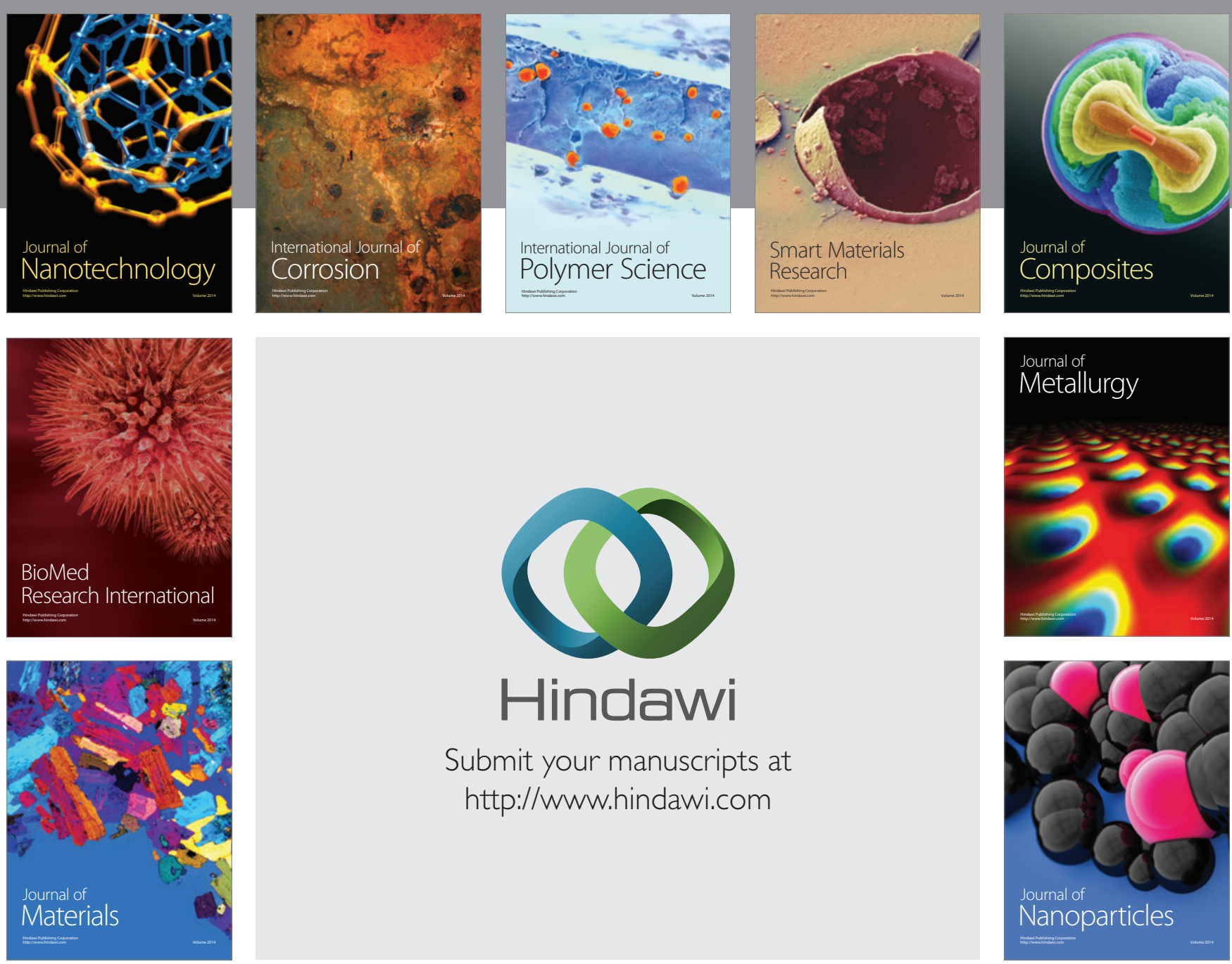

Submit your manuscripts at http://www.hindawi.com
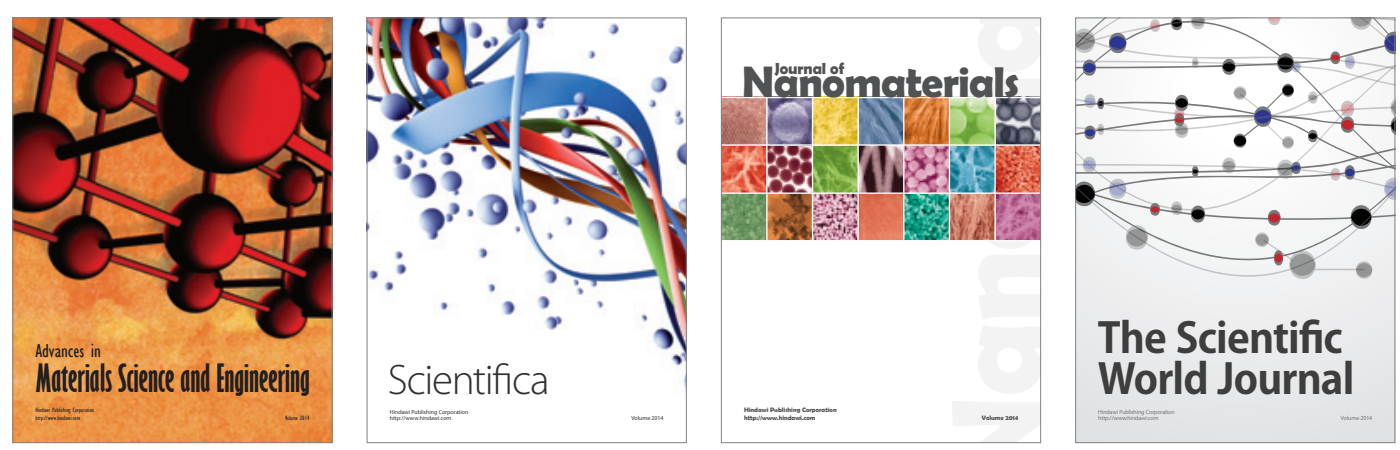

\section{The Scientific World Journal}
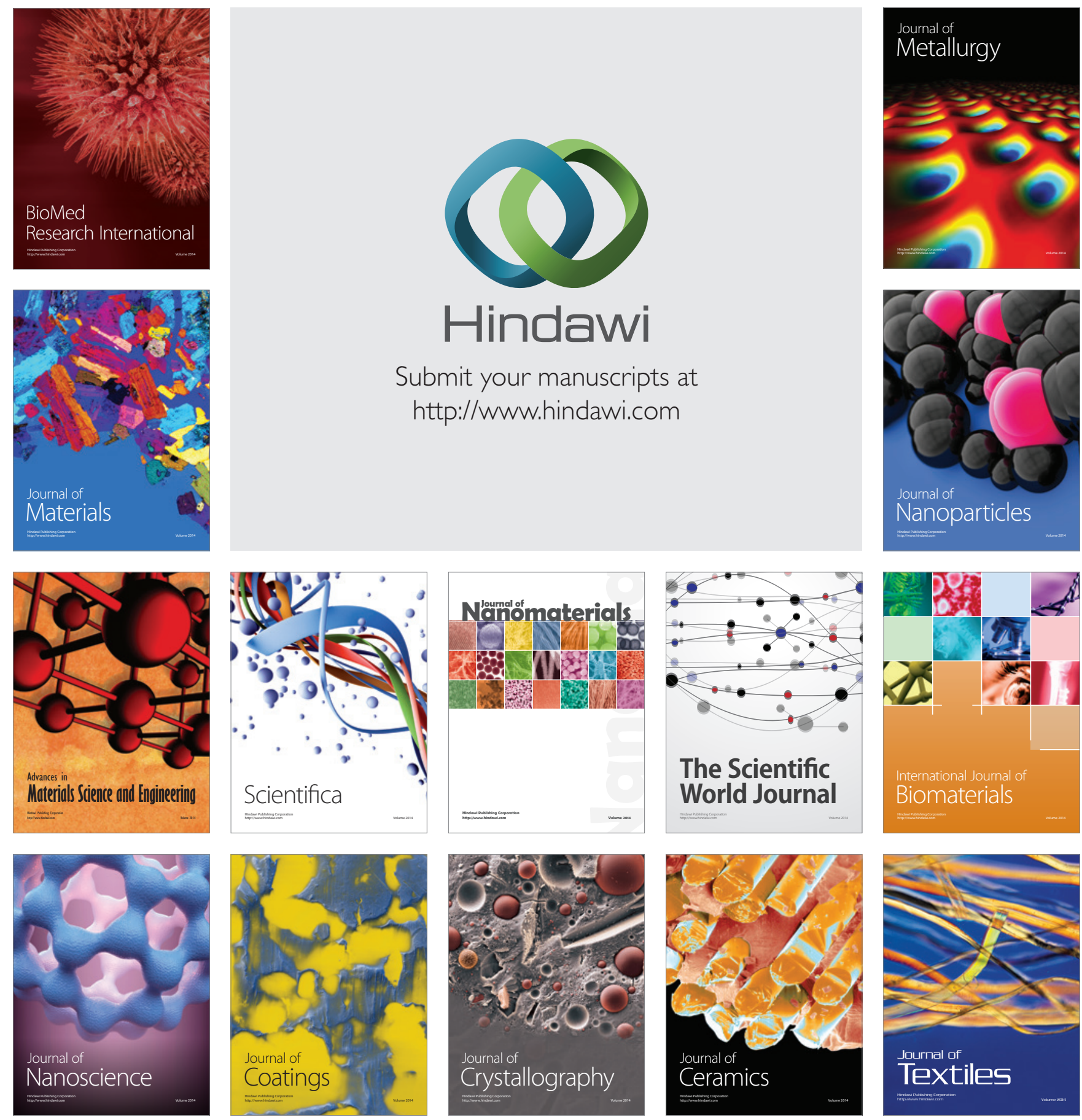